\title{
Disability as a Precursor to Mental Health Challenges
}

Ibraheem Abiodun Salako*

University of Ibadan College of Medicine, Institute of Child Health, Nigeria

\begin{abstract}
Introduction: Disability is a controversial topic of discourse in recent times as a result of documented tremendous increase in the incidence rates of conditions that leave individuals with significant limitations or restrictions in functioning. Research has shown that health needs of persons with disabilities may vary depending on the nature of their disability which if left unattended to may lead to conditions that compound the effects of the disability such as mental health problems.
\end{abstract}

Objective: The primary aim of this study is to narrative review of qualitative studies on the incidence of mental health problems amongst the disabled category.

Methods: Keyword searches of Pubmed database, manual searches of reference lists of related articles.

Results: Data gathered revealed that persons with disabilities are more likely than others to experience mental health problems which may be as a result of the psychological burden associated with the condition and/or the effects of the medications that are been used to suppress the disabling condition.

Conclusion: Quality of life measures should be carried out on every individual in the disabled category. Mental health service should be provided early enough and focus on identified specific health needs of each individual involved so as to cushion the effects of disability, improve mental health outcomes and ultimately, the quality of life experienced by persons with disabilities.

\section{Concept of Disability and Mental Health}

A disability can be said to be a physical or mental condition that limits a person's functional abilities in the areas of movements, senses and activities. Disabilities place individuals at a disadvantage because it excludes them from adapting into the normal environment of their regular peers. It is often caused by a variety of factors which are not limited to accidents, illnesses, maternal factors, etc. Some people are born with disabling conditions or may present a disabling condition early in life (i.e., Developmental disabilities) while others may acquire disabilities through injury. Also, some others develop disabilities later in life as a result of progressive diseases or illnesses, therefore, people with disabilities can be said to be a diverse group who share the experience of living with significant limitations in functioning and, as a result, often experience exclusion from full participation in their communities [1].

Disability is a phenomenon that has received much attention lately due to the unending discourse on the attribution of a specific and limited meaning to the word. However, it has received much attention lately as a result of the higher incidence rate of conditions which the word 'disability' covers. Australian Institute of Health and Welfare found that about 296,400 children or $7.6 \%$ of children aged $0-14$ years, were estimated to have intellectual and/or learning disabilities. Mont also revealed that global estimates indicate that around $10 \%$ of people live with a disability and which the number is still growing as a result of a number of factors including increased survival rates for children and increased population life expectancies [2-5]. A more recent publication by Lewis for the Rehabilitation Research and Training Center on Disability Statistics and Demographics reported that the percentage of people with disabilities in the US population rose from $11.9 \%$ in 2010 to $12.6 \%$ in 2013,2014 and 2015 [6]

The health needs of persons with disabilities vary depending on the nature of their disability which if left unattended lead to conditions that may compound the effects of the disability such as mental health problems. Mental Health is a state that describes the psychological wellbeing of an Individual. The psychological wellbeing encompasses both the social and emotional adjustment to everyday life challenges, stress and some other factors associated with life in general. The World Health Organization defined mental health as a state of well-being in which every individual realizes his or her own potential, can cope with the normal stresses of life, can work productively and fruitfully, and is able to make a contribution to his or her community [7]. The U.S Department of Human services defined mental health as the successful performance of mental function, resulting in productive activities, fulfilling relationships with other people and providing the ability to adapt to change and cope with adversity [8].

Mental health can be seen as an unstable continuum, where an individual's mental health may have many different possible values and its prevalence have been found to increase with a child's age [9]. Singh et al, [10] revealed that approximately $19.6 \%$ of adolescents aged $12-17 \mathrm{had}$ mental health problems, compared with $15.9 \%$ of children aged 6-11 and $6.7 \%$ of children aged 3-5 years in the US. This finding is comparable to an earlier study by the National Adolescent Health Information Centre survey which found that over 1 in 10 (11.6\%) adolescents ages 12-17 had serious behavioral or mental health difficulties, as rated by parents using a modified version of the Strengths and Difficulties Questionnaire when put into consideration the population increase across the years [11]. Also, a more recent survey by the National Institute for Mental Health, NIMH recorded an approximate of 1 in 5 youth aged 13-18

*Corresponding author: Ibraheem Abiodun Salako, University of Ibadan College of Medicine, Institute of Child Health, Nigeria, Tel: 2348151863072; E-mail: ibbsalako@yahoo.com

Received June 14, 2017; Accepted July 19, 2017; Published July 26, 2017

Citation: Salako IA (2017) Disability as a Precursor to Mental Health Challenges. Health Care Current Reviews 5: 201. doi: 10.4172/2375-4273.1000201

Copyright: $\odot 2017$ Salako IA. This is an open-access article distributed under the terms of the Creative Commons Attribution License, which permits unrestricted use, distribution, and reproduction in any medium, provided the original author and source are credited. 
(21.4\%) that may experience a severe mental disorder at some point during their life [12]. Such mental disorders are often characterized by alterations in thinking; mood or behaviour associated with distress or impaired functioning. All these studies have concordant findings that all point towards the high incidence of poor mental health outcomes amongst our young adults, which may be a precursor to the low quality of life observed.

Optimum mental health is seen as a very important factor in a person's everyday life as it positively impacts social skills, emotional skills and many other skills that are needed to behave like an average person. Therefore, the aim of this study is to review related literature on the incidence of mental health problems amongst the disabled category and based on the findings recommend a working mental health intervention program targeted towards improving the quality of life of persons with handicapping conditions.

\section{Poor Mental Health as a Consequence of Disability}

In the past, substantial literature has focused on mental health problems amongst regular children and adolescents. However, some recent studies have identified a relationship between mental health and disability. Emerson and Hatton found that about $36 \%$ of British children with intellectual disability have a diagnosable mental health disorder when compared with $8 \%$ of other children. Similarly, the national mental health survey in Australia indicated that $29 \%$ of people with disabilities reported an anxiety disorder and $17 \%$ reported an affective disorder in the last twelve months compared to $12 \%$ and $4 \%$ respectively for people with no disability or no specific limitations or restrictions and that about $59 \%$ of people with common mental disorders in Australia also have physical conditions $[13,14]$. While there is a great deal of heterogeneity in the mental health outcome across varying disability groups, a number of studies have documented a higher risk of negative mental health outcomes in the 'disabled' group when compared to other regular people [15-19]. Chan et al. [19] conducted a study on a specific disability group, those with intellectual disabilities and findings revealed that there is an increased risk of mental health problems amongst his population. A prospective study by Andelic et al. [20] conducted on 85 patients with moderate to severe traumatic brain injury (TBI) revealed that about $37 \%$ of patients reported poor mental health 1 year after injury. Earlier studies carried out on TBI has a risk factor of mental health problems also provided equivalent findings [21,22]. Lucas [23] conducted a longitudinal study to support the idea that disability contributes to poor mental health and found in a large sample of British adults, that psychological distress increased significantly after disability onset. While there was evidence of a gradual reduction in distress over time, distress was still higher 4 years after disability onset than at baseline. Furthermore, some studies have reported higher incidence of mental health problems after the onset of potentially disabling physical illness, including myocardial infarction, stroke, HIV infection, spinal pain, neurologic diseases and gastrointestinal diseases [24-26]. A recent survey by the WHO World Mental Health Survey Collaborators has also documented a strong association between disability and psychotic experiences regardless of the presence of comorbid mental or general medical disorders [27].

\section{Conclusion}

Review of literature has shown that persons with disabilities are more likely than others to experience mental health problems due to the psychological burden associated with the condition and/or the effects of the medications that are being used to suppress the disabling condition
$[24,28]$. Also, mental disorders may share common risk factors with other health conditions and disabilities. In view of this, quality of life measures should be carried out on every individual afflicted with an injury, illness or disease that falls within the disabled category, and an early intervention program must be provided for those identified to be at risk. Mental health service provided should be based on identifying specific health needs of each individual involved so as to cushion the effects of disability, improve mental health outcomes and ultimately, the quality of life experienced by persons with disabilities. Further research needs to be carried out to investigate the interactions between medications used to suppress disabling conditions and poor mental health outcomes while putting into consideration other risk factors.

\section{Methods}

A narrative review was undertaken and 15 studies were included in the review. The studies were identified by keyword searches of the PubMed database. Keywords searched include "Mental health" and "disability". Manual searches of reference lists of primary articles found from initial searches were also conducted.

\section{References}

1. Krahn L, Walker D, Correa-De-Araujo R (2015) Persons with disabilities as an unrecognized health disparity population. Am J Public Health 105: S198-S206.

2. Mont $D$ (2007) Measuring disability prevalence. Washington: World Bank.

3. Children with disabilities in Australia. AlHW.

4. Perrin JM (2002) Health services research for children with disabilities. Milbank Q 80: 303-324.

5. Sawyer S, Drew S, Yeo MS, Britto MT (2007) Adolescents with a chronic condition: Challenges living, challenges treating. Lancet 369: 1481-1489.

6. Lewis K (2017) 2016 Disability statistics annual report.

7. World Health Organization (2014) Mental health: A state of health of well-being

8. U.S Department of Health and Human services (1999) Mental Health: A report of the surgeon-general.

9. Keyes CLM (2002) The mental health continuum: From languishing to flourishing in life. J Health Soc Behav 43: 207-222.

10. Singh K, Kenney MK, Ghandour M, Kogan D, Lu C (2013) Mental health outcomes in US children and adolescents born prematurely or with low birth weight. Depress Res Treat.

11. National Adolescent Health Information Centre (2004) National health interview survey.

12. http://www.nimh.nih.gov/health/statistics/prevalence/any-disorder-amongchildren.shtml

13. Emerson E, Hatton C (2007) Mental health of children and adolescents with intellectual disabilities in Britain. Br J Psychiatry 191: 493-499.

14. Australian Bureau of Statistics. Mental Health and Wellbeing Survey 2007 Canberra: ABS 2008.

15. Emerson E, Honey A, Llewellyn G (2008) The well-being and aspirations of Australian adolescents and young adults with a long-term health condition, disability or impairment. Canberra: Australian Research Alliance for Children and Youth.

16. Honey A, Emerson E, Llewellyn G, Kariuki M (2010) Mental health and disability.

17. Miauton L, Narring F, Michaud PA (2003) Chronic illness, life style and emotional health in adolescence: Results of a cross-sectional survey on the health of 15-20 year olds in Switzerland. Eur J Pediatr 162: 682-689.

18. Wolman C, Resnick MD, Harris LJ, Blum RW (1994) Emotional well-being among adolescents with and without chronic conditions. J Adolesc Health 15: 199-204.

19. Chan J, Parmenter T, Stancliffe R (2009) The impact of traumatic brain injury on the mental health outcomes of individuals and their family carers. AeJAMH 8: $1-10$ 
20. Andelic N, Sigurdardottir S, Schanke AK, Sandvik L, Sveen U, et al. (2010) Disability, physical health and mental health 1 year after traumatic brain injury. Disabil Rehabil 32: 1122-1131.

21. Cooper SA, Smiley E, Morrison J, Williamson A, Allan L (2007) Mental ill-health in adults with intellectual disabilities: Prevalence and associated factors. $\mathrm{Br} J$ Psychiatry 190: 27-35.

22. Kolaitis G (2008) Young people with intellectual disabilities and mental health needs. Curr Opin Psychiatry 21: 469-473.

23. Lucas RE (2007) Long-term disability is associated with lasting changes in subjective well-being: Evidence from two nationally representative longitudinal studies. J Pers Soc Psychol 92: 717-730.

24. Prince M, Patel V, Saxena S, Maj M, Maselko J, et al. (2007) No health without mental health. Lancet 370: 859-877.
25. Carroll LJ, Cassidy JD, Cote P (2003) Factors associated with the onset of an episode of depressive symptoms in the general population. J Clin Epidemio 56: 651-658.

26. Bruce ML, Hoff RA (1994) Social and physical health risk factors for first-onset major depressive disorder in a community sample. Soc Psychiatry Psychiatr Epidemiol 29: 165-171.

27. Navarro-Mateu F, Alonso J, Lim CCW, Saha S, Aguilar-Gaxiola S, et al. (2017) The association between psychotic experiences and disability: Results from the WHO world mental health surveys. WHO World Mental Health Survey Collaborators 136: 74-84.

28. Malek-Ahmadi P, Hilsabeck RC (2007) Neuropsychiatric complications of interferons: Classification, neurochemical bases and management. Ann Clin Psychiatry 19: 113-123. 